\section{Commentary: Management of the aortic arch in Loeys-Dietz and Marfan syndromes}

\author{
Leora B. Balsam, MD
}

When looking for advice on how to manage the aortic arch in patients undergoing proximal aortic surgery, it is clear that patient-specific and center-specific factors matter. The presence of a connective tissue disorder, dissection involving the arch, or arch aneurysm are patient-specific factors that may influence the extent of resection. In some situations, prophylactic aortic arch surgery may make sense, assuming that the risk of the additional procedure is low, the likelihood of needing arch surgery in the future is high, and the risk of reintervention is at least the same or greater than the risk of the prophylactic procedure. Center-specific factors, such as local surgical expertise and culture, may also influence decisions regarding the scope of surgery.

In a recent publication in the Journal, the Hopkins group describes their approach for managing the aortic arch in patients with Loeys-Dietz syndrome (LDS) and Marfan syndrome (MFS). ${ }^{1}$ The group has a uniquely large surgical experience with these patients and lessons have been learned along the way. Over a 20 -year period, they performed aortic operations on 79 patients with LDS and 256 patients with MFS. Although the group has previously described their experience with patients with LDS, ${ }^{2}$ the present study expands upon that by comparing the outcomes with patients with MFS.

LDS is caused by mutations in genes within the transforming growth factor beta signaling axis, whereas MFS is caused by fibrillin-1 mutations. Certain genetic mutations in LDS are associated with a more aggressive aortopathy,

\footnotetext{
From the Division of Cardiac Surgery, UMass Memorial Medical Center, Worcester, Mass.

Disclosures: The author reported no conflicts of interest.

The Journal policy requires editors and reviewers to disclose conflicts of interest and to decline handling or reviewing manuscripts for which they may have a conflict of interest. The editors and reviewers of this article have no conflicts of interest.

Received for publication July 23, 2020; revisions received July 23, 2020; accepted for publication July 23, 2020; available ahead of print July 25, 2020.

Address for reprints: Leora B. Balsam, MD, Division of Cardiac Surgery, UMass Memorial Medical Center, University Campus, 55 Lake Ave North, Worcester, MA 01655 (E-mail: leora.balsam@umassmemorial.org).

J Thorac Cardiovasc Surg 2020;160:1179-80 $0022-5223 / \$ 36.00$

Copyright (c) 2020 Published by Elsevier Inc. on behalf of The American Association for Thoracic Surgery

https://doi.org/10.1016/j.jtcvs.2020.07.075
}

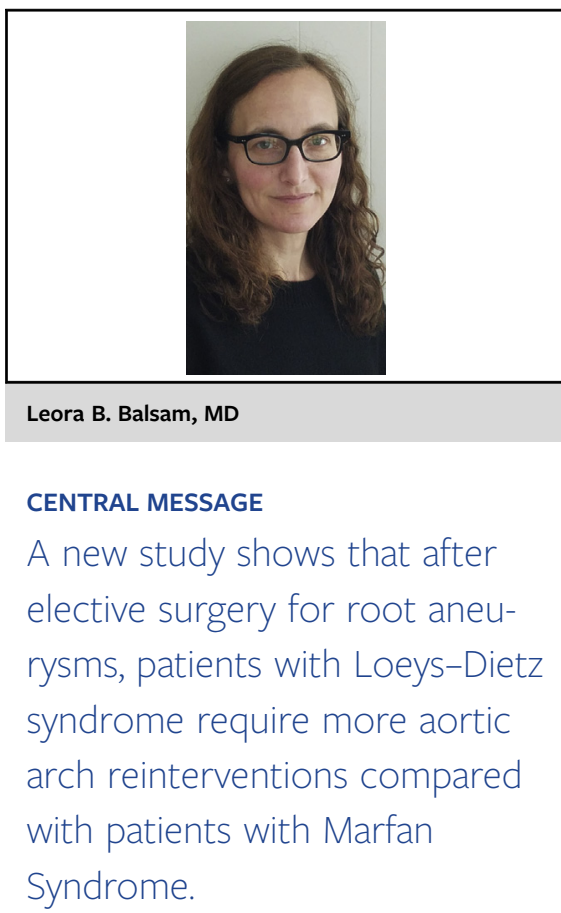

with dissection and rupture occurring at younger ages and smaller aortic diameters. In addition, the presence of arterial tortuosity, hypertelorism, and wide scars increases the risk of aortic events. ${ }^{3}$ The Hopkins group has a nuanced approach for determining when to perform elective aortic root surgery in patients with LDS, with factors such as genetic mutation, rate of aneurysm growth, and phenotypic characteristics being considered. Weighing those factors, aortic root surgery may be recommended at aortic dimensions of 40 to $45 \mathrm{~mm}$. For MFS, a threshold of 45 to $50 \mathrm{~mm}$ is used.

Others have shown that the risk of secondary intervention on the aortic arch is small after elective root surgery in MFS; however, the risk is markedly increased in the presence of dissection. In their single-center experience, Bachet and colleagues ${ }^{4}$ found that $16 \%$ of patients with MFS required secondary arch replacement after elective root replacement, compared with $73 \%$ in patients with MFS who presented for their index operation with a type A aortic dissection. Schoenhoff and colleagues ${ }^{5}$ from Berne, Switzerland reported a similar pattern, with $1.6 \%$ of MFS patients undergoing secondary total arch replacement after elective root surgery, compared to $33 \%$ in MFS patients with history of aortic dissection. The Hopkins group finds that for both LDS and MFS, the presence of type A dissection before or after the index operation increases the likelihood of arch reinterventions 12 -fold. ${ }^{1}$ In both LDS and 
MFS patients with known arch dissection at the time of root surgery, extending the proximal repair into the arch should be considered.

Among patients undergoing elective root surgery, the Hopkins group finds that concomitant arch replacement occurred more frequently in the LDS group than the MFS group $(4.4 \%$ vs $0.4 \%)$. In addition, the frequency of secondary arch intervention was significantly greater in the LDS group than the MFS group $(12 \%$ vs $1.3 \%)$, with a mean time to reintervention of 7 years. ${ }^{1}$ The authors conclude that a more aggressive approach toward arch resection at the time of elective proximal repair is warranted in patients with LDS. They specifically recommend hemiarch repair, which may be influenced by their opinion that commercially available branched arch grafts do not fit well in children. They also noted in their previous publication that many of the patients with LDS who required secondary arch interventions had normal size arches at the time of the original intervention. ${ }^{2}$ In the current study, they state that the principal reasons for reoperation were dilation of the non-resected distal ascending aorta/proximal arch or pseudoaneurysm with distal suture-line dehiscence.

This study also adds to our understanding of how prophylactic surgery for proximal aortic disease affects long-term survival in LDS and MFS. Survival is significantly better in patients without aortic dissections undergoing elective repair. This points to the importance of preventing dissection using established tools such as beta blockers, angiotensin receptor blockers, imaging surveillance, and guideline-directed prophylactic root surgery. In addition, the study finds that in LDS, but not patients with MFS, the need for secondary arch intervention is associated with worse long-term survival. Future studies are needed to quantify the risk of arch intervention at the time of elective root surgery compared to later reintervention.

\section{References}

1. Schoenhoff FS, Alejo DE, Black JH, Crawford TC, Dietz HC, Grimm JC, et al. Management of the aortic arch in patients with Loeys-Dietz syndrome. J Thorac Cardiovasc Surg. 2020;160:1166-75.

2. Patel ND, Crawford T, Magruder JT, Alejo DE, Hibino N, Black J, et al. Cardiovascular operations for Loeys-Dietz syndrome: intermediate-term results. $J$ Thorac Cardiovasc Surg. 2017;153:406-12.

3. Jondeau G, Ropers J, Regalado E, Braverman A, Evangelista A, Teixedo G, et al. International registry of patients carrying TGFBR1 or TGFBR2 mutations: results of the MAC (Montalcino Aortic Consortium). Circ Cardiovasc Genet. 2016;9: 548-58.

4. Bachet J, Larrazet F, Goudot B, Dreyfus G, Folliguet T, Laborde F, et al. When should the aortic arch be replaced in Marfan patients? Ann Thorac Surg. 2007; 83:S774-9.

5. Schoenhoff FS, Kadner A, Czerny M, Jungi S, Meszaros K, Schmidli J, et al. Should aortic arch replacement be performed during initial surgery for aortic root aneurysm in patients with Marfan syndrome? Eur J Cardiothorac Surg. $2013 ; 44: 346-51$. 